\title{
Influence of fish oil supplementation and strength training on some functional aspects of immune cells in healthy elderly women
}

\author{
Cintia de Lourdes Nahhas Rodacki ${ }^{1,2}$, André Luiz Felix Rodacki ${ }^{1 *}$, Isabela Coelho ${ }^{1}$, Daniele Pequito ${ }^{1}$, \\ Maressa Krause $^{2}$, Sandro Bonatto ${ }^{3}$, Katya Naliwaiko ${ }^{1}$ and Luiz Cláudio Fernandes ${ }^{1}$ \\ ${ }^{1}$ Paraná Federal University, Setor de Ciências Biológicas, Rua Coração de Maria, 92 - Jardim Botânico, Curitiba, \\ Paraná, Brazil \\ ${ }^{2}$ Department of Physical Education, Paraná Technological Federal University, Curitiba, Paraná, Brazil \\ ${ }^{3}$ Pelé - Pequeno Príncipe Research Institute, Curitiba, Paraná, Brazil \\ (Submitted 28 July 2014 - Final revision received 25 March 2015 - Accepted 9 April 2015 - First published online 10 June 2015)
}

\section{Abstract}

Immune function changes with ageing and is influenced by physical activity (strength training, ST) and diet (fish oil, FO). The present study investigated the effect of FO and ST on the immune system of elderly women. Forty-five women (64 (SD 1.4) years) were assigned to ST for $90 \mathrm{~d}$ (ST; $n$ 15), ST plus $2 \mathrm{~g} / \mathrm{d}$ FO for $90 \mathrm{~d}$ (ST90; $n$ 15) or $2 \mathrm{~g} / \mathrm{d}$ FO for $60 \mathrm{~d}$ followed by ST plus FO for $90 \mathrm{~d}$ (ST150; $n$ 15). Training was performed three times per week, for 12 weeks. A number of innate (zymosan phagocytosis, lysosomal volume, superoxide anion, peroxide of hydrogen) and adaptive (cluster of differentiation 4 (CD4), CD8, TNF- $\alpha$, interferon- $\gamma$ (IFN- $\gamma$ ), IL-2, IL- 6 and IL-10 produced by lymphocytes) immune parameters were assessed before supplementation (base), before (pre-) and after (post-) training. ST induced no immune changes. FO supplementation caused increased phagocytosis (48\%), lysosomal volume (100\%) and the production of superoxide anion $(32 \%)$ and $\mathrm{H}_{2} \mathrm{O}_{2}(70 \%)$ in the ST90. Additional FO supplementation (ST150) caused no additive influence on the immune system, as ST150 and ST90 did not differ, but caused greater changes when compared to the ST $(P<0 \cdot 05)$. FO increased CD $4^{+}$ and $\mathrm{CD}^{+}$lymphocytes in the ST150, which remained unchanged when training was introduced. The combination of ST and FO reduced TNF- $\alpha$ in the ST150 from base to post-test. FO supplementation (ST150, base-pre) when combined with exercise (ST150, pre-post) increased IFN- $\gamma$, IL-2, IL-6 and IL-10 production. The immune parameters improved in response to FO supplementation; however, ST alone did not enhance the immune system.

Key words: Fish oil: Immune system: Strength training

Ageing is often associated with a deregulated immune system that has a pronounced impact on general health, as it increases likelihood of infectious, chronic degenerative, autoimmune and malignant diseases ${ }^{(1,2)}$. Senescence may influence both the innate and adaptive immune function. Innate immunity changes include impaired phagocytosis and reactive oxygen species (ROS) production by neutrophils, which diminish their ability to destroy pathogens ${ }^{(3,4)}$. Adaptive immune system responses to age include an inverted CD4:CD8 T-cell ratio, decreased number and function of the T- and B-lymphocytes and low levels of IL-2 production ${ }^{(5,6)}$.

Physical activity and diet are proposed to play a relevant role in modulating immune system responses ${ }^{(2,5-8)}$. Moderate physical activity has been reported to increase T-cell proliferation, antibody response to vaccination, production of anti-inflammatory cytokines and IL-2 production ${ }^{(5-9)}$. On the other hand, excessive exercise has been proven to produce an exacerbated inflammatory response ${ }^{(9,10)}$. Resistance exercise training interventions have been widely used and a series of neuromuscular benefits have been identified. There are many mechanistic possibilities that could account for enhanced immunity by regular strength training (ST) exercise. Immune enhancement may occur due to exercise effects on body fat and mass distribution, lipid metabolism, plasma hormones, cholesterol and peripheral circulation. Indeed, increasing body mass and plasma leptin concentrations are inversely correlated with leucocyte telomere length ${ }^{(6)}$, while changes in the cholesterol content of plasma cell membranes can alter the functionality of a series of cells of the immune system ${ }^{(11)}$.

Exercise programmes designed to improve muscular function using moderate intensity have presented inconsistent results ${ }^{(9,10)}$. Several shorter-term interventions (10 weeks-6 months)

Abbreviations: 1RM, one maximal repetition; Abs, absorbance; ES, effect size; FO, fish oil; IFN- $\boldsymbol{\gamma}$, interferon- $\boldsymbol{\gamma}$; ROS, reactive oxygen species; ST, strength training.

*Corresponding author: Professor A. L. F. Rodacki, fax + 55413360 4336, email rodacki@ufpr.br 
involving ST (three sets of eight repetitions per set) have failed to increase natural killer cell function, T-cell proliferation, IL-2 production and the number or percentage of $\mathrm{CD}^{+}$and $\mathrm{CD}^{+}$ lymphocytes ${ }^{(7,12-15)}$. On the other hand, improved lymphocyte proliferation and natural killer cytotoxicity were found after a period of 6 months of moderate $\mathrm{ST}^{(16-18)}$. Kohut et $a l .{ }^{(19)}$ found increased immune function in response to exercise, when comparing a group of elderly who exercised using low-intensity loads and a sedentary age-matched group.

Fish oil (FO) supplementation rich in $n$-3 PUFA has been shown to influence the immune system responses ${ }^{(20-22)}$. Modifying the fatty acid intake leads to altered fatty acid composition of the immune cells ${ }^{(23)}$, which leads to increased membrane phospholipid fatty acid content. Changing the physical properties of the membrane influences cell signalling pathways modifying the expression and the transduction of intracellular signalling mechanisms ${ }^{(24)}$. The $n-6$ PUFA, linoleic acid, is a precursor of arachidonic acid, which is a substrate of cyclooxygenase and lipoxygenase enzymes that cause a net pro-inflammatory environment and damage in several tissues ${ }^{(8,25)}$. Therefore, the association of physical activity and FO rich in $n$-3 PUFA supplementation may produce larger improvements in the immune system than when exercise and diet are applied independently. Thus, the present study aimed to investigate the effect of FO supplementation and its association with an ST programme performed at moderate intensity on the innate (neutrophils) and the adaptive immune system (CD4, CD8, TNF- $\alpha$, interferon- $\gamma$ (IFN- $\gamma$ ), IL-2, IL-6 and IL-10 produced by T lymphocytes) in elderly women. It was hypothesised that FO supplementation rich in $n-3$ PUFA associated with ST would improve immune system function in ageing women.

\section{Methods}

\section{Participants}

Forty-five healthy Caucasian women (64.0 (SD 1.4) years old) participated in the present study after signing an informed consent form. The present study was conducted according to the guidelines laid down in the Declaration of Helsinki, and all procedures were approved by the Positivo University Ethics
Committee. Participants were selected by convenience from the waiting list of a free physical training programme offered by the University using the application order to invite participants. The sample was limited to forty-five participants due to operational training issues and complexity of an interventional protocol that required a large number of measurements and supplementation. A physician screened all participants who were deemed in good health to undergo an ST programme. Participants were not under hormone replacement therapy, drug therapy that could influence the results or were engaged in any other regular physical activity programme in the 12 months that preceded the study. The participants were asked to maintain their normal eating habits and physical activity level throughout the study. The physical characteristics and dietary habits of the participants are reported in Table 1.

In the first session, participants were first interviewed at the laboratory and they answered the International Physical Activity Questionnaire ${ }^{(26)}$. In an attempt to obtain homogeneous groups, forty-four participants were randomly assigned to one of the three experimental groups, after being classified in quartiles according to their relative knee extension strength (one repetition maximal/body weight) ${ }^{(27)}$. The remaining subject (lowest performance) was allocated in the last quartile before the assignment was completed. Physical characteristics and physical activity level were similar between groups before starting the training programme $(P>0.05)$. One group performed only ST ( $n 15 ; 64.9$ (SD 1.0$)$ years), while another was supplemented with FO throughout the $90 \mathrm{~d}$ of the ST (ST90; $n$ 15; 63.8 (SD 1.4) years). Finally, one group received $\mathrm{FO}$ supplementation $60 \mathrm{~d}$ before starting the ST and then for $90 \mathrm{~d}$ during ST (ST150; $n$ 15; 63.3 (SD 2.0) years). The ST90 and the ST150 followed identical training programmes (90 d). The FO supplement contained $180 \mathrm{~g}$ EPA and $120 \mathrm{~g} \mathrm{DHA} / \mathrm{kg}$. The supplemented groups received $2 \mathrm{~g} / \mathrm{d}$ of FO (one capsule during each main meal), which provided approximately $0.4 \mathrm{~g}$ EPA and $0.3 \mathrm{~g} \mathrm{DHA} / \mathrm{d}$.

The programme included supervised ST exercises performed three times per week, for 12 weeks, in a total of thirty-six sessions. Diet was monitored by using food diary of a day before and after training to ensure that there was no change in dietary intake. Diet was monitored with FFQ completed pre- and post-training to ensure that there was no change in dietary

Table 1. Body mass, BMl and dietary habits of the participants of the strength training (ST), strength training and 90 (ST90) and 150 (ST150) d of $n-3$ fatty acid supplementation groups before (pre) and after (post) training

(Mean values and standard deviations; $n$ 15)

\begin{tabular}{|c|c|c|c|c|c|c|c|c|c|c|c|c|c|}
\hline & \multicolumn{4}{|c|}{ ST } & \multicolumn{4}{|c|}{ ST90 } & \multicolumn{4}{|c|}{ ST150 } & \multirow[b]{3}{*}{$P^{\star}$} \\
\hline & \multicolumn{2}{|c|}{ Pre } & \multicolumn{2}{|c|}{ Post } & \multicolumn{2}{|c|}{ Pre } & \multicolumn{2}{|c|}{ Post } & \multicolumn{2}{|c|}{ Pre } & \multicolumn{2}{|c|}{ Post } & \\
\hline & Mean & SD & Mean & SD & Mean & SD & Mean & SD & Mean & SD & Mean & SD & \\
\hline Body mass $(\mathrm{kg})$ & 65.9 & 1.0 & $65 \cdot 1$ & $1 \cdot 3$ & 66.8 & 1.4 & $66 \cdot 2$ & 1.6 & $67 \cdot 3$ & $2 \cdot 0$ & $66 \cdot 1$ & 1.7 & 0.96 \\
\hline BMI $\left(\mathrm{kg} / \mathrm{m}^{2}\right)$ & $25 \cdot 4$ & 1.6 & $25 \cdot 7$ & $1 \cdot 7$ & $27 \cdot 7$ & 1.3 & $26 \cdot 8$ & 1.5 & $25 \cdot 7$ & $1 \cdot 1$ & $25 \cdot 2$ & 1.4 & 0.56 \\
\hline Protein $(\mathrm{g})$ & 52 & 21 & 57 & 20 & 54 & 19 & 57 & 18 & 58 & 22 & 55 & 19 & 0.77 \\
\hline Lipids (g) & 63 & 20 & 61 & 21 & 63 & 18 & 60 & 20 & 58 & 19 & 61 & 21 & 0.81 \\
\hline Total energy & & & & & & & & & & & & & 0.76 \\
\hline $\mathrm{kcal}$ & 1470 & 380 & 1480 & 395 & 1490 & 412 & 1510 & 430 & 1515 & 408 & 1475 & 395 & \\
\hline $\mathrm{kJ}$ & 6150 & 1590 & 6192 & 1653 & 6234 & 1724 & 6318 & 1799 & 6339 & 1707 & 6171 & 1653 & \\
\hline
\end{tabular}

*Values refer to differences between groups (ST, ST90 and ST150) two-way ANOVA. 
intake. Innate immune cell function (zymosan phagocytosis, lysosomal volume, superoxide anion, $\mathrm{H}_{2} \mathrm{O}_{2}$ ) was evaluated in the ST and ST90 groups before (pre-) and after (post-) training. The ST150 was evaluated on three occasions: pre-supplementation (base $-60 \mathrm{~d}$ before initiating pre-training period), pre-training (at 60th day to coincide with pre-) and post-training (at 150th day to coincide with post-).

Adaptive immune parameters $\left(\mathrm{CD}^{+}\right.$and $\mathrm{CD}^{+}$ lymphocytes cytokines TNF- $\alpha$, IFN- $\gamma$, IL-2, IL- 6 and IL-10 produced by lymphocyte) were evaluated only in the ST150 group on three occasions (base, pre- and post-training).

Special care was taken so that the participants involved in the present study did not come into contact with other groups during training or blood collection to minimise the chances of psychological effects. In addition, groups trained on different weekdays. Participants received specially worded consent forms to ensure that they were unaware of the existence of other experimental groups. A placebo was not provided because (1) there was no contact between groups and (2) there was no suitable placebo available to the experimenters for FO supplementation. Providing any other oil could cause its incorporation into the cell membranes and increase oil consumption, which has been associated with the development of chronic diseases $^{(28)}$. All participants completed the experimental procedures and no dropouts occurred. Fig. 1 shows the schematic representation of the study design and allocation of participants.

\section{Plasma and fish oil capsule fatty acid composition}

The composition of the fatty acids in the FO capsules and plasma were assessed by HPLC (Varian ProStar). Total lipids were extracted from the FO capsules and plasma of volunteers by using chloroform:methanol (2:1, v/v). Fatty acids were derivatised with 4-bromomethyl-7-coumarin and then separated using an octadecylsilica column $(25 \mathrm{~cm}$, $4.6 \mathrm{~mm}$ internal diameter; particle size: $5 \mathrm{~lm}$ ). Fatty acids were resolved isocratically by using a mobile phase of acetonitrile-water (gradient from 77:23 to 90:10, v/v) at a flow rate of $1 \mathrm{ml} / \mathrm{min}$. Fatty acid derivatives were detected by fluorescence $(325 \mathrm{~nm}$ excitation, $395 \mathrm{~nm}$ emission), as previously described ${ }^{(22)}$. The analysis showed the presence of the following fatty acids in the capsules provided to the participants: lauric $(12: 0), 7 \cdot 0$ (SD 0.1)\%; myristic (14:0), amount not determined; palmitic (16:0), 14.2 (SD 1.9)\%; stearic (18:0), 1.4 (SD 0.4)\%; palmitoleic (16:1n-7), amount not determined; oleic (18:1n-9), 10.6 (SD 1.1)\%; linoleic (18:2n-6), 3.3 (sD 0.3)\%; $\alpha$-linolenic (18:3n-3), amount not determined; arachidonic (20:4n-6), 13.7 (SD 0.8)\%; EPA (22:5n-3), 29.5 (sD 0.7)\%; DHA (22:6n-3), $23 \cdot 6$ (sD 0.2)\%.

\section{Strength training programme}

The one maximal repetition (1RM) test was performed in the first training session after a brief warm-up. The participants were familiarised with the ST exercises for six sessions ( 2 weeks) by performing three sets of eight repetitions at $50 \%$ of their 1RM load. After the familiarisation period, 12 weeks of ST were introduced. The initial training week included three sets of eight repetitions at $70 \%$ of 1 RM. Training load was increased in the 2nd week to $80 \%$ of $1 \mathrm{RM}$ and was adjusted on a weekly basis (every three sessions) from the 3 rd to the last week of training. These procedures have been used in other studies involving muscle strengthening in the elderly ${ }^{(27)}$. The sessions were performed under the supervision of one researcher and under the guidance of two qualified instructors.

The training sessions included the following exercises: bilateral hip adduction and abduction, unilateral hip flexion and extension, bilateral horizontal leg press, bilateral knee flexion and extension, and bilateral plantar flexion. Exercises included concentric and eccentric phases using standard pulley-type devices (Athletic $\left.{ }^{\circledR}\right)$. Verbal encouragement was provided in all sessions. The exercise loads were recorded throughout the study to quantify load increases.

\section{Evaluation of immune parameters}

Reagents, enzymes and solutions. The reagents used in the preparation of solutions were obtained from Reagen (Quimibrás Industria Química Ltda). PBS solution, pH 7•4, 10 mm was used as dilution medium for the dye. The zymosan, neutral red, phenol red, nitrobluetetrazolium, oxylenol orange, butylatedhydroxytoluene and bovine serum albumin were from Sigma-Aldrich. Concanavalin A was obtained from Sigma-Aldrich, while culture medium (RPMI 1640), antibiotics (penicillin and streptomycin) and fetal bovine serum were obtained from Gibco. The capsules of FO were provided by the Herbarium Foundation ${ }^{\circledR}$ and each capsule contained 0.165-0.137 g of EPA and DHA.

Isolation of plasma and polymorphonuclear cells. The blood samples were taken before (pre) and after (post) the training period for the ST90 and ST groups after at least $8 \mathrm{~h}$ of fasting. However, the ST150 group was assessed at three different times: before supplementation (base), pre-training (day 60) and post-training (day 150). The participants' blood samples were collected by a nurse in previously heparinised tubes (Eppendorf model BD - 410R) and kept refrigerated. Isolation of neutrophils was performed as suggested by Boyum $^{(29)}$. The blood was centrifuged in the same collection tube at $1200 \mathrm{rpm}$ for $10 \mathrm{~min}$ at $4^{\circ} \mathrm{C}$. Part of the remaining plasma was aliquoted and transferred to another $50 \mathrm{ml}$ Falcon tube and the same volume of PBS was added.

As much as $8 \mathrm{ml}$ of blood diluted in PBS was layered onto a $3 \mathrm{ml}$ Ficoll-Paque PLUS (GE Healthcare Bio-Sciences). The tubes were centrifuged at $400 \mathrm{~g}$ at $4^{\circ} \mathrm{C}$ for $30 \mathrm{~min}$. The transparent top layer was discarded. The bottom layer consisting of erythrocytes and polymorphonuclear cells was transferred to another tube. The samples were submitted twice to hypotonic lysis by incubation with haemolytic solution (Tris base hydroxymethylaminomethane $17 \cdot 0$ and $18 \cdot 7-\mathrm{mm} \mathrm{NH}_{4} \mathrm{Cl}$ ) in a water bath at $37^{\circ} \mathrm{C}$ for $15 \mathrm{~min}$. The solution was centrifuged at $153 \mathrm{~g}$ for $10 \mathrm{~min}$. The supernatant was discarded and the cells re-suspended in PBS and counted in a Neubauer chamber. Once isolated, the polymorphonuclear cells were stained (May-Grünwald Giemsa) and determined by optical microscopy. Viability was determined by Trypan staining ( $0.2 \%$ in PBS) and was greater than $95 \%{ }^{(29)}$. 


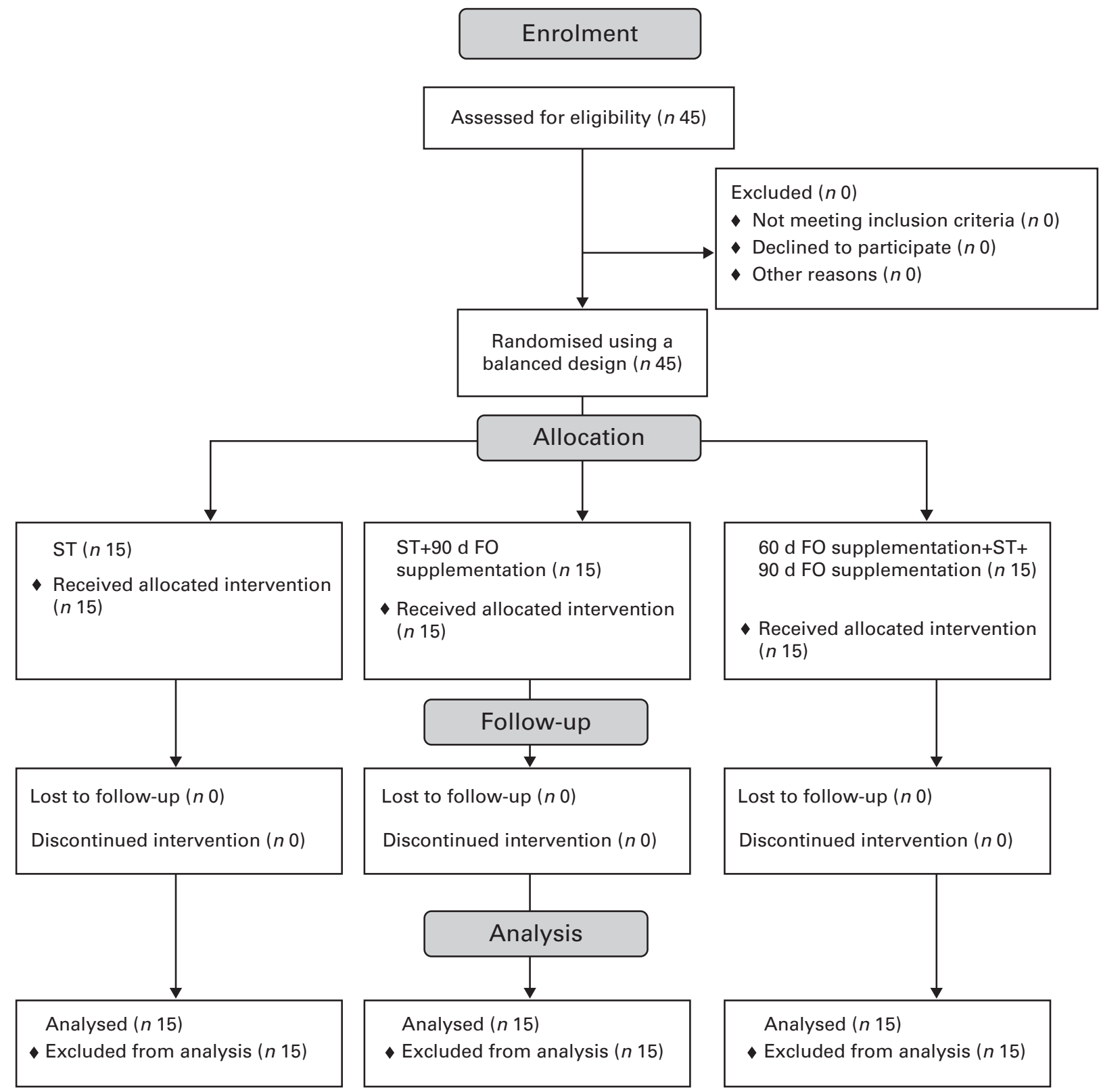

Fig. 1. Flow of participants through the study. ST, strength training; FO, fish oil.

Zymosan phagocytosis by neutrophils. Neutrophils were seeded in ninety-six-well, flat-bottomed, tissue culture plates $\left(2 \times 10^{5}\right.$ cells in $\left.0 \cdot 1 \mathrm{ml}\right)$. Neutral red-stained zymosan ( $10 \mu \mathrm{l}$ containing $10^{6}$ particles) was added and the plates incubated for $30 \mathrm{~min}$. The cells were fixed with Baker's formol-calcium solution ( $4 \%$ formaldehyde, $2 \% \mathrm{NaCl}, 1 \%$ calcium acetate) for $30 \mathrm{~min}$ and centrifuged at $\mathbf{4 5 3} \mathbf{g}$ for $5 \mathrm{~min}$. The neutral red stain was extracted by $0 \cdot 1 \mathrm{ml}$ of acidified alcohol ( $10 \%$ acetic acid, $40 \%$ ethanol in distilled water) for $30 \mathrm{~min}$. The absorbance (Abs) was read on a microplate reader at $550 \mathrm{~nm}$. Phagocytosis was calculated from a standard curve of stained zymosan and results expressed as Abs $/ 10^{6}$ cell per $\mathrm{ml}^{(30)}$.

Lysosomal volume of neutrophils. The assessment of neutrophil lysosomal volume system was previously described by Bonatto et al. ${ }^{(30)}$. Briefly, $2 \times 10^{5}$ cells (in $0.1 \mathrm{ml}$ ) were incubated for $30 \mathrm{~min}$ in $20 \mu \mathrm{l}$ of neutral red (3\% in PBS) and then washed twice with PBS by centrifugation ( $453 \boldsymbol{g}$ for $5 \mathrm{~min}$ ). Neutral red was solubilised in $0.1 \mathrm{ml}$ of ethanolacetic acid (40:10\%, v/v). The Abs was read at $550 \mathrm{~nm}$ and lysosomal volume was expressed as Abs $/ 10^{6}$ cell per ml.

Superoxide anion production by neutrophils. Neutrophils production of superoxide anion was measured by the reduction of nitrobluetetrazolium ${ }^{(31)}$. The neutrophils $\left(2 \times 10^{5}\right.$ in $\left.0 \cdot 1 \mathrm{ml}\right)$ suspended in PBS were incubated for $1 \mathrm{~h}$ at $37^{\circ} \mathrm{C}$ in the presence of $10 \mu \mathrm{l}$ of phorbolmyristyl acetate ( $4 \mathrm{lM}$ final concentration) and $0 \cdot 1 \%(\mathrm{w} / \mathrm{v})$ nitrobluetetrazolium. Then the mixture was centrifuged for $5 \mathrm{~min}$ at $453 \mathbf{g}$ and the cells were fixed with $50 \%$ methanol for $10 \mathrm{~min}$ and then air-dried and centrifuged as before. Reduction of nitrobluetetrazolium results in the formation of blue for mazan, 
which was solubilised by $30 \mathrm{~min}$ incubation with $120 \mu \mathrm{l}$ of $2-\mathrm{M}$ potassium hydroxide and $140 \mu$ l of dimethyl sulfoxide per well. The Abs was read at $550 \mathrm{~nm}$. The results are expressed as Abs $/ 10^{6}$ cell per ml.

$\mathrm{H}_{2} \mathrm{O}_{2}$ production by neutrophils. $\mathrm{H}_{2} \mathrm{O}_{2}$ production by neutrophils was measured as described previously by Pick and Mizel ${ }^{(31)}$. This assay is based on the horseradish peroxidase-dependent conversion of phenol red into a coloured compound by $\mathrm{H}_{2} \mathrm{O}_{2}$. Neutrophils $\left(2 \times 10^{5}\right.$ in $\left.0 \cdot 1 \mathrm{ml}\right)$ were incubated in the presence of glucose $(5 \mathrm{~mm})$, phenol red solution $(0.56 \mathrm{~mm})$ and horseradish peroxidase $(8.5 \mathrm{U} / \mathrm{ml})$ in the dark for $1 \mathrm{~h}$ at $37^{\circ} \mathrm{C}$. After this period, the Abs was measured at $620 \mathrm{~nm}$ on a plate reader. The concentration of $\mathrm{H}_{2} \mathrm{O}_{2}$ was determined from a standard curve prepared in parallel. The results are expressed as $\mathrm{mol} / 10^{6}$ cell per $\mathrm{ml}$.

Cytokines. Lymphocytes were stimulated with concanavalin A $(5 \mathrm{mg} / \mathrm{ml})$ and lipopolysaccharide $(5 \mathrm{mg} / \mathrm{ml})$ to final volume of $2 \mathrm{ml}$ for $24 \mathrm{~h}$ plates $(2 \times 105$ cells per well). At the end of the culture period, the plates were centrifuged to separate the cells from the medium. Aliquots of cells were cultured, concanavalin A and lipopolysaccharide of medium were frozen $\left(-70^{\circ} \mathrm{C}\right)$ for subsequent analysis of cytokines by flow cytometry as instructed by Cytometric Bead Array kit BD $^{\mathrm{TM}}$ CBA to, IL-2, IL-6, IL-4, IL-10, TNF- $\alpha$ and IFN- $\gamma$ (Clontech Laboratories, Inc. - BD Bioscience). The results were expressed as $\mathrm{pg} / \mathrm{ml}$.

Analysis of surface markers. Quantitative determination of the surface marker for T-helper lymphocytes $\left(\mathrm{CD} 4^{+}\right)$and T cytotoxic lymphocytes ( $\mathrm{CD}^{+}$cells) was performed by flow cytometry ${ }^{(29)}$. Lymphocytes were re-suspended in PBS and incubated for 30 min with monoclonal antibodies against $\mathrm{CD}^{+}$, labelled with phycoerythrin (fluorescent orange-red; detector FL2; 585 $(\mathrm{sD} 42) \mathrm{nm}$ ) and against $\mathrm{CD}^{+}$labeled with fluorescein isothiocyanate (green fluorescence; FL1 detector; 530 (sD 30) nm).
Excess antibody was removed by washing with PBS azide buffer $(0.05 \%)$

\section{Statistical analysis}

After confirming data normality and variance homogeneity, a number of ANOVA (two-factor ANCOVA), with group (ST, ST90 and ST150) and time (pre- and post-training) as factors were conducted, with the last factor treated as a repeated measure. The pre-test data were used as covariate. A dependentsample $t$ test was used for ST150 group data to compare the dependent variables before the supplementation period (baseline; base) with the pretest data (pre-test). This approach was introduced in order to determine the effect of FO supplementation in the selected parameters without the ST effects. The innate immune cells function data were analysed using an ANCOVA, with the pre-training data as a covariate and group as a factor. Effect size (ES) was also calculated using the Cohen's $d$ approach. The Bonferroni-corrected $t$ test was applied to identify where differences occurred. Statistical analyses were performed by using Statistica software (version 7.0; Statsoft, Inc.). The significance level was set at $P<0 \cdot 05$.

\section{Results}

All participants had high attendance (>95\%) and no dropouts were observed. Body mass and dietary habits remained unchanged from pre- to post-training in all groups $(P>0.05)$. The total mean energy, protein and lipid intake were similar between groups (group effect; $P>0.05$, ES $>0.8$ ) and did not change after the training period (time effect; $P>0 \cdot 05$, ES $>0 \cdot 8$; Table 1 ).

Plasma fatty acid profiles for all groups are shown in Table 2. The ST group showed no change in EPA or DHA $(P>0.05$, ES $>0 \cdot 7)$. The ST90 group experienced significant increases

Table 2. Fatty acid composition (\%) of plasma from participants measured in fasting in the strength training (ST), strength training and 90 (ST90) and 150 (ST150) d groups $\ddagger$

(Mean values and standard deviations; $n$ 15)

\begin{tabular}{|c|c|c|c|c|c|c|c|c|c|c|c|c|c|c|}
\hline \multirow[b]{3}{*}{ Fatty acids } & \multicolumn{4}{|c|}{ ST } & \multicolumn{4}{|c|}{ ST90 } & \multicolumn{6}{|c|}{ ST150 } \\
\hline & \multicolumn{2}{|c|}{ Pre§ } & \multicolumn{2}{|c|}{ Post§ } & \multicolumn{2}{|c|}{ Pre } & \multicolumn{2}{|c|}{ Post } & \multicolumn{2}{|c|}{ Base§ } & \multicolumn{2}{|c|}{ Pre } & \multicolumn{2}{|c|}{ Post } \\
\hline & Mean & SD & Mean & $\overline{S D}$ & Mean & SD & Mean & SD & Mean & SD & Mean & SD & Mean & SD \\
\hline$\alpha$-Linolenic (18:3n-3) & 0.7 & 0.2 & 1.0 & 0.8 & 0.8 & 0.2 & $0 \cdot 8$ & 0.6 & 0.9 & 0.5 & $1 \cdot 1$ & 0.5 & $1 \cdot 2$ & 0.5 \\
\hline Arachidonic $(20: 4 n-6)$ & 3.1 & 0.1 & 2.9 & 0.1 & $2 \cdot 8$ & 0.2 & 2.5 & 0.7 & $2 \cdot 6$ & $1 \cdot 2$ & $2 \cdot 5$ & 0.9 & $2 \cdot 4$ & 0.6 \\
\hline $\mathrm{DHA}(22: 6 n-3)$ & $6 \cdot 1$ & 1.3 & $5 \cdot 3$ & 1.5 & 6.5 & $1 \cdot 1$ & $7 \cdot 8^{*}$ & $1 \cdot 1$ & $5 \cdot 6$ & $1 \cdot 1$ & $8.4 \dagger$ & 1.5 & $7.9 \dagger$ & $1 \cdot 2$ \\
\hline EPA $(20: 5 n-3)$ & 1.7 & 0.2 & $1 \cdot 1$ & 0.4 & $1 \cdot 1$ & 0.2 & $1 \cdot 6^{*}$ & 0.3 & 0.8 & 0.2 & $1.7 \dagger$ & 0.4 & $1.8 \dagger$ & 0.3 \\
\hline Stearic $(18: 0)$ & $2 \cdot 7$ & 0.4 & 2.5 & 1.3 & $2 \cdot 8$ & 0.2 & 2.9 & 0.2 & $3 \cdot 1$ & 1.0 & 3.4 & $1 \cdot 2$ & $3 \cdot 1$ & 0.7 \\
\hline Lauric $(12: 0)$ & $25 \cdot 2$ & 4.4 & 25.5 & 3.8 & $26 \cdot 1$ & $4 \cdot 1$ & 24.9 & 3.7 & $22 \cdot 7$ & 3.8 & $22 \cdot 3$ & 3.1 & 21.9 & 3.9 \\
\hline Linoleic $(18: 2 n-6)$ & 23.0 & 1.5 & $22 \cdot 4$ & $1 \cdot 1$ & $22 \cdot 6$ & 1.0 & 21.5 & 2.3 & $22 \cdot 4$ & 3.9 & 21.5 & $2 \cdot 2$ & $20 \cdot 3$ & 2.4 \\
\hline Myristic (14:0) & 4.1 & $2 \cdot 7$ & $6 \cdot 2$ & $2 \cdot 1$ & $5 \cdot 1$ & $1 \cdot 6$ & $6 \cdot 1$ & 1.9 & $5 \cdot 2$ & 1.9 & $6 \cdot 1$ & 1.9 & $5 \cdot 8$ & $2 \cdot 4$ \\
\hline Oleic $(18: 1 n-9)$ & 20.4 & $2 \cdot 8$ & $19 \cdot 2$ & $2 \cdot 1$ & $20 \cdot 3$ & $2 \cdot 1$ & $20 \cdot 2$ & 1.9 & $18 \cdot 7$ & 1.8 & 18.5 & 1.9 & $18 \cdot 2$ & 1.9 \\
\hline Palmitic $(16: 0)$ & 13.9 & 0.2 & $13 \cdot 0$ & $1 \cdot 3$ & $12 \cdot 7$ & $1 \cdot 2$ & 12.6 & 0.4 & $14 \cdot 2$ & $3 \cdot 2$ & $15 \cdot 1$ & $2 \cdot 1$ & $14 \cdot 3$ & $2 \cdot 0$ \\
\hline Palmitoleic $(16: 1 n-7)$ & $1 \cdot 2$ & $0 . \overline{5}$ & 0.9 & 0.3 & 1.4 & $0 . \overline{5}$ & 1.3 & 0.2 & 1.3 & 0.5 & 1.5 & 0.7 & 1.4 & 0.5 \\
\hline
\end{tabular}

* Mean value is significantly different from that of pre-training $(P<0.05)$

$\dagger$ Mean value is significantly different from that of base $(P<0.05)$.

$\ddagger$ A two-way ANOVA for repeated measures was used to identify differences between factors (group and time) and the Bonferroni corrected $t$ test applied to determine where differences occurred. A $t$ test for dependent samples was applied to compare base and pre-test of the group ST150.

$\S$ Base refers to the data collected $60 \mathrm{~d}$ before initiating the training period; pre refers to the data collected immediately before starting the training programme; post refers to the data collected after the end of the training programme. 
(a)

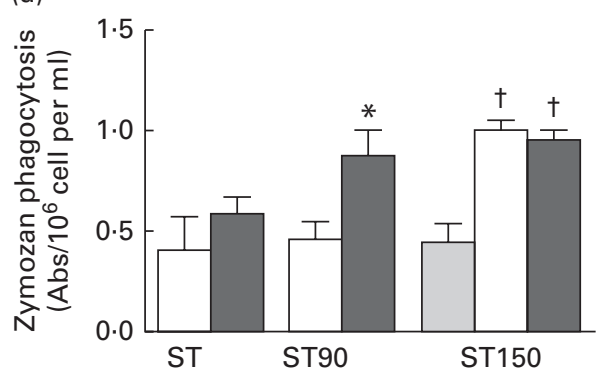

(c)

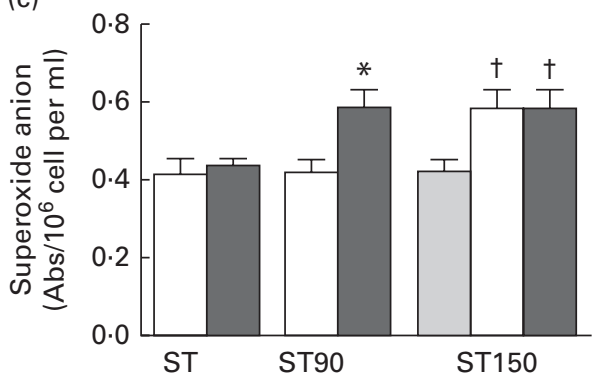

(b)

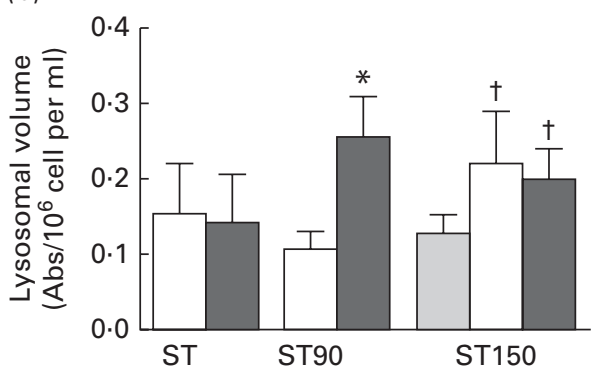

(d)

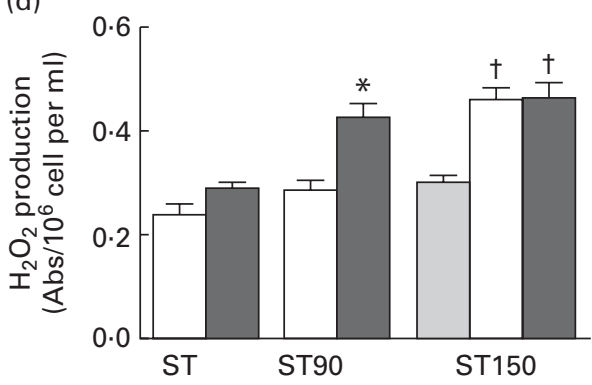

Fig. 2. (a) Zymozan phagocytosis, (b) lysosomal volume, (c) superoxide anion production, (d) $\mathrm{H}_{2} \mathrm{O}_{2}$ production (reactive oxygen species) by neutrophils obtained from blood of elderly groups undergoing strength training (ST, $n$ 15), trained force and were supplemented with fish oil (FO) for 90 (ST90, $n$ 15) and 150 (ST150, $n$ 15) d; base line (base, $\square$ ), supplemented with FO for $60 \mathrm{~d}$ before training (pre, $\square$ ) supplemented with FO and after training (post, $\square$ ). Values are means with their standard errors represented by vertical bars. ${ }^{*}$ Mean value is significantly different from that at pre group $(P<0.05)$. †Mean value is significantly different from that at base group $(P<0.05)$. A two-factor ANOVA for repeated measures was applied to identify differences between factors (group and time) and the Bonferroni $t$ test was applied to determine where the differences occurred. The $t$ test for repeated measures revealed differences $(P<0.05)$ between the base and pre group ST150. Abs, absorbance.

$(P<0 \cdot 05$, ES $>0 \cdot 7)$ in EPA and DHA concentrations in the plasma after FO supplementation (post-) of 45 and $20 \%$, respectively. The ST150 group also showed significant mean increases in EPA and DHA concentrations in the plasma after FO supplementation (from base to pre-training) of 112 and 50\%, respectively. No changes were observed in EPA and DHA in the ST150 group from pre- to post-training $(P>0 \cdot 05, \mathrm{ES}=0 \cdot 7)$.

The changes in immune system are presented in Fig. 2 . The ST (pre-post) group showed no changes between conditions before and after training (time effect) in innate immune cells function $(P>0.05$, ES $>0.7)$. The group ST90 (pre-post) showed significant changes $(P<0.05)$ in phagocytosis $(48 \%)$, lysosomal volume $(100 \%)$ and production of superoxide anion (32\%) and $\mathrm{H}_{2} \mathrm{O}_{2}$ (70\%). The group ST150 (base-pre) showed significant changes $(P<0.05$, ES $>0.7)$ in phagocytosis (50\%), lysosomal volume (95\%) and production of superoxide anion (43\%) and $\mathrm{H}_{2} \mathrm{O}_{2}$ (85\%). The prolonged period of supplementation (ST150, pre-post) caused no additive effect on innate immune cells, because both supplemented groups (ST150 and ST90) showed similar changes $(P>0.05$, ES $>0 \cdot 7)$, but were significantly higher when compared with ST (effect interaction, $P<0 \cdot 05$ ).

The CD 4 and CD8 lymphocytes are presented in Fig. 3 and show that FO supplementation caused increases in the population of $\mathrm{CD}^{+}$and $\mathrm{CD}^{+}$lymphocytes $(P<0.05$, ES $>0.7)$, which remained unchanged when supplementation was combined with exercise training $(P>0.05$, ES $>0.6)$.

The combination of exercise and FO reduced TNF- $\alpha$ production in the ST150 from base to post. FO supplementation (ST150, base-pre) and its combination with exercise (ST150, pre-post) increased IL-2, IL-6 and IL-10 production. These parameters are represented in Fig. 4.
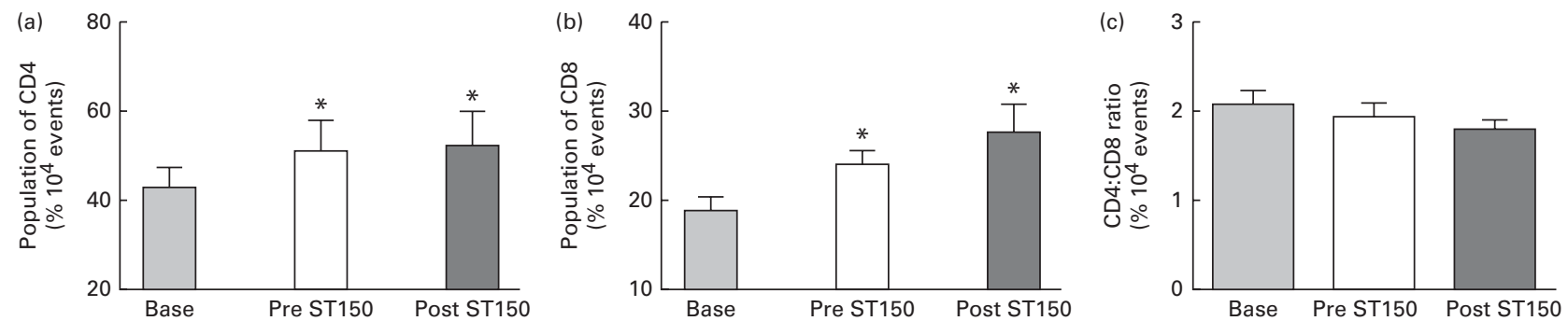

Fig. 3. Population of cluster of differentiation $4^{+}\left(\mathrm{CD} 4^{+}\right)$and $\mathrm{CD} 8^{+}$group subjected to strength training (ST) before (base), after receiving supplementation fish oil (FO) for $150 \mathrm{~d}$ (pre ST150; $n$ 15) and after receiving FO supplementation associated with a resistance exercise programme (post ST150; $n$ 15). (a) Population of CD4, (b) population of CD8 and (c) CD4:CD8 ratio. Values are means with their standard errors represented by vertical bars. *Mean value is significantly different from that at base group $(P<0.05)$. A repeated measures ANOVA was applied to identify differences between the effect of groups (time) and the Bonferroni $t$ test was applied to determine where the differences occurred. 

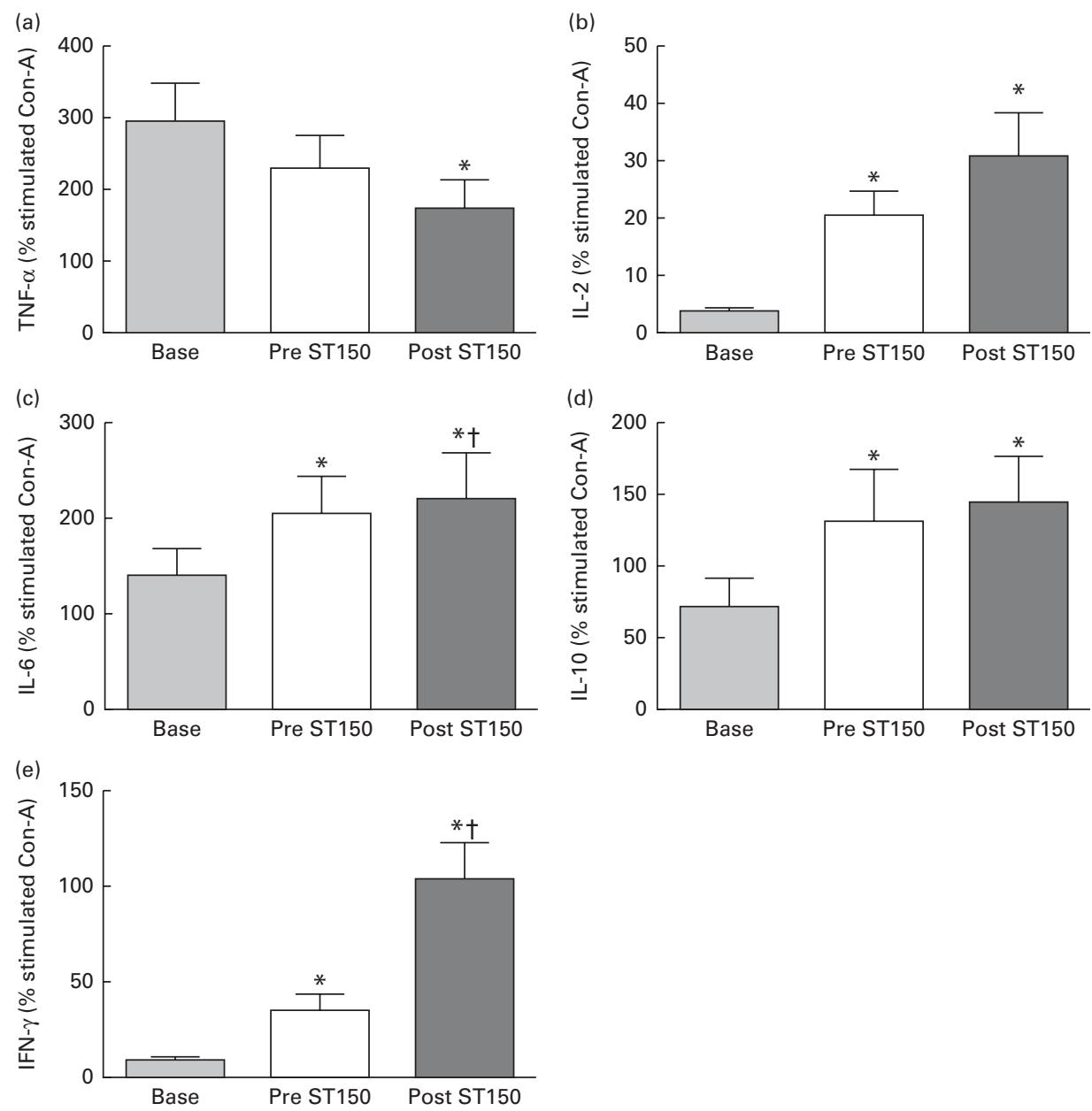

Fig. 4. (a) TNF- $\alpha$, (b) IL-2, (c) IL-6, (d) IL-10 and (e) interferon- $\gamma$ (IFN- $\gamma$ ) production in the group that was subjected to fish oil (FO) supplementation for $60 \mathrm{~d}$ followed by FO supplementation and strength training (ST) for $90 \mathrm{~d}$ (150 d in total; ST150 group). Production before supplementation (base), after receiving fish oil supplementation (pre ST150; $n$ 15) and after receiving fish oil supplementation associated with strength training (post ST150; $n$ 15). Values are means, with standard deviations represented by vertical bars. A repeated-measures ANOVA was applied to identify differences between the effect of groups (time) and the Bonferroni $t$ test was applied to determine where the differences occurred. ${ }^{*}$ Mean value was significantly different from that at base group $(P<0.05)$. $\dagger$ Mean value was significantly different from that at pre group $(P<0.05)$. Con-A, concanavalin A.

\section{Discussion}

Neutrophils represent $50-60 \%$ of the pool of circulating leucocytes and constitute the first line of host defence against bacterial infection. Neutrophils destroy pathogens through phagocytosis, degranulation and release of ROS. Advancing age is associated with a reduction in neutrophil functional capability such as phagocytic and microbiocidal activities, most likely due to a concomitant reduction in the production of ROS caused by impaired $\mathrm{Ca}^{2+}$ flux during cell signalling ${ }^{(3)}$.

In the present study, these parameters were tested in a group of elderly women who performed physical exercises (ST) and the other two groups that received FO supplementation and performed physical exercises (ST90 and ST150). The group that only exercised did not present changes in these immune parameters, which is in contrast with the reports that used extensive periods of training (e.g., 1 year) and also applied moderate-intensity exercises ${ }^{(32)}$. It is possible that long-term moderate physical exercise increases IL- 2 and IL- 6 production that stimulate the production and function of neutrophils and the other immune parameters. In fact, some studies showed a higher proliferation of mitogen-stimulated peripheral blood mononuclear cells in elderly runners in comparison to their sedentary peers ${ }^{(33)}$. Phagocytic activity was found better preserved in elderly who exercised when compared to controls $^{(34)}$. Cross-sectional and longitudinal studies have shown that habitual exercise is associated with a greater production of IL-2 in the elderly ${ }^{(35,36)}$.

Studies that used short training programmes ( 24 weeks) failed to demonstrate consistent improvements in proliferative responses in older adults ${ }^{(37,38)}$. Thus, regular physical activity for months or even years may help to counter the age-related decline in immune function. Although this might indicate that exercise has limited immune restorative properties in sedentary elderly $^{(39,40)}$, its duration, intensity and exercise type may constitute relevant aspects that may influence the immune responses. Strenuous exercises may cause adverse effects due to intense stress hormone release that decrease neutrophil and lymphocyte proliferation, ratio of $\mathrm{CD}^{+} \mathrm{CD}^{+}$and antibody production $^{(37,38,40)}$. Although some studies have demonstrated 
a negative impact of strenuous exercises on the immune system $^{(12-14)}$. Kapasi et al. ${ }^{(41)}$ found no effect of 32-week endurance and resistance exercise programme in frail elderly nursing home residents (age 87 years) on $\mathrm{CD}^{+}{ }^{+}$or CD8 ${ }^{+} \mathrm{T}$-cells. Similarly, Raso et $a l^{(42)}$ found no differences in the absolute number of $\mathrm{CD}^{+}$or $\mathrm{CD}^{+} \mathrm{T}$-cells in sedentary elderly women (aged 60-77 years) after completing 12 months of moderate-intensity resistance training. The exercise training intervention could account for enhanced immunity by changing body mass distribution, lipid metabolism, plasma hormones, cholesterol content of plasma cell membranes and plasma leptin ${ }^{(14,43)}$. Several of these markers are inversely correlated with leucocyte telomere length and lymphocytes proliferative responses ${ }^{(43)}$

The exercise training applied in the present study did not modify the other parameters of immune system (CD4, CD8, TNF- $\alpha$, IFN- $\gamma$, IL-2, IL- 6 and IL-10 produced by T lymphocytes) in the group of elderly women (ST). For instance, Flynn et al. ${ }^{(7)}$ and Rall et al. ${ }^{(14)}$ conducted a training programme in a group of elderly women and observed improvements in strength, but no changes were found on the immune parameters. It must be emphasised the positive aspects of strength improvements due to the beneficial influence on daily life activity and risk of fall reduction ${ }^{(44)}$ and the fact that active elderly have fewer infections and lower incidence of cancer than their sedentary peers ${ }^{(12)}$

In the present study, it was observed that FO supplementation improved the immune system by increasing the functioning of neutrophils, the proliferation of $\mathrm{CD}^{+}$and $\mathrm{CD} 8^{+}$lymphocytes and the production of lymphocyte cytokines ${ }^{(21-23,45)}$.

The phagocytic activity of neutrophils improved in response to $2 \mathrm{~g} / \mathrm{d}$ of FO supplementation (ST90 $48 \%$ and ST150 49\%), which is in line with other studies that used similar doses $^{(30,32,46)}$. Increasing FO intake may boost the incorporation of EPA and DHA in the cell membrane ${ }^{(46,47)}$. Calder ${ }^{(45,48)}$ found that cells with larger amounts of SFA in their membranes and less amounts of EPA and DHA present lower ability to emit pseudopodia and are less able to perform phagocytosis. In addition, membrane fluidity is increased and the formation of pseudopodia and phagocytosis is facilitated ${ }^{(45)}$.

In the present study, the functionality of the immune system was observed by lysosomal uptake of neutral red secretory vesicles. FO intake caused lysosomal volume increase (ranging from 90 to $145 \%$ ). The group that was supplemented with FO during 8 weeks before starting the exercise programme also experienced lysosomal volume increases, which were comparable with the group that exercised and was supplemented. In addition, the relatively unchanged lysosomal volume at the end of the training period in the group that received FO supplementation before initiating the training programme is a strong indicator that these gains were primarily caused by the FO.

The improved functioning of the neutrophils of the supplemented groups is further evidenced by the improved phagocytic activity. Shaikh \& Edidin $^{(49)}$ revealed that FO supplementation is able to change the structure of the Golgi complex membrane and to increase the production of secretory vesicles and organelle transport to the plasma membrane.

The data from the present study show that supplementation with FO caused increased production of superoxide anion in both supplemented groups (ST90 32\% and ST150 43\%). These findings are explained by the fact that $\mathrm{FO}$ can modulate the activity of NADPH oxidase. Low production of ROS means a decreased microbicidal capacity and consequently diminished ability of the neutrophils to act against pathogens. FO has been shown to increase the activity of antioxidant enzymes and also to modulate the concentrations of $\operatorname{ROS}^{(50,51)}$. In addition, dismutase superoxide can be rapidly converted to $\mathrm{H}_{2} \mathrm{O}_{2}$ and may have provided a more pronounced antimicrobial function than the superoxide anion ${ }^{(52)}$. Therefore, it is relevant to the analysis of the production of ROS, superoxide anion and $\mathrm{H}_{2} \mathrm{O}_{2}$. The supplemented groups showed increased $\mathrm{H}_{2} \mathrm{O}_{2}$ production. Another contributing factor to reduced production of ROS in the elderly is decreasing intracellular $\mathrm{Ca}^{2+}$ in the neutrophils in the elderly ${ }^{(53,54)}$. Ageing is accompanied by increased viscosity of the plasma membrane, leading to decrease in fluidity ${ }^{(55)}$. Thus, it is possible that increasing the intake of $n-3$ improved the fluidity of the cell membrane, receptor function and mobility of intracellular $\mathrm{Ca}^{2+}$ in the neutrophils ${ }^{(55,56)}$.

Cytotoxic $\mathrm{T}$ lymphocytes $\left(\mathrm{CD}^{+}\right)$recognise intracellular infection and have the function to destroy infected cells, while the $\mathrm{T}$ helper cells $\left(\mathrm{CD}^{+}\right)$organise the immune response. The elderly appear to present reduced $\mathrm{CD}^{+}{ }^{+}$compared to $\mathrm{CD}^{+}$ cell population, which has been linked to malnutrition and suppressed immune response in the elderly. Supplementing elderly with $\mathrm{FO}$ increased the population of $\mathrm{CD}^{+}(25 \%)$ and $\mathrm{CD}^{+}(23 \%)$ lymphocytes, which remained unaffected when supplementation with FO was combined with exercise training. These results confirm the arguments that FO is an immune stimulator $^{(23)}$. The mechanism by which FO alters the proliferation of $\mathrm{T}$ cells is still unclear. A possible mechanism may be based on the fact that increasing the intake of EPA decreases the production of eicosanoids derived from arachidonic acid, which is related to increased inflammatory responses. In addition, EPA derivatives have a relevant regulatory action on the immune system ${ }^{(23)}$. In fact, the immunomodulatory effects of $n-3$ fatty acids can be observed even at very low doses in elderly subjects ${ }^{(57)}$.

The release of cytokines is essential for the initiation of the immune response and for the regulation of multidirectional communication between different cells ${ }^{(58)}$. Thus, dysfunction of the cytokine network - a regular finding in the elderly ${ }^{(59)}$ - can disrupt the immune system, leading to chronic inflammation and compromising health ${ }^{(59,60)}$. Chronic inflammation is present in the ageing process, and elevated baseline concentrations of IL- 6 and C-reactive protein in the elderly are associated with higher risks of morbidity and mortality ${ }^{(60)}$. On the other hand, maintaining low basal levels of cytokines seems to be related to health and longevity ${ }^{(59)}$.

The data from the present study revealed that FO tends to reduce the production of TNF- $\alpha$. These results are consistent with the results indicated by Grimble et $a l{ }^{(58)}$, who observed a decrease in inflammatory biomarkers by consumption of EPA and DHA (derived from FO). The high amount of EPA and DHA allows increased production of eicosanoids or cytokines, with less inflammatory actions ${ }^{(58,59)}$. In addition to the anti-inflammatory effect of FO, moderate physical exercise also has this effect because the cytokine (IL-6) produced by the muscle during muscular contraction reduces the 
production of TNF- $\alpha^{(60,61)}$. Therefore, it may be part of the mechanisms by which exercise has anti-inflammatory effects. Unfortunately, it was impossible to measure the isolated effect of exercise on TNF- $\alpha$. Thus, it can be suggested that the combination of $\mathrm{FO}$ and exercise caused changes in the production of TNF- $\alpha$ and have a significant impact on the elderly health. Considered that, elevated concentration of TNF- $\alpha$ may be the key to develop metabolic syndrome characterised by abdominal obesity, hypertension, low HDL, high TAG and high concentration of fasting glucose. TNF- $\alpha$ is also related to the reduction of muscle tissue (sarcopenia) ${ }^{(61)}$.

In the present study, other cytokines analysed were IL-2 and IFN- $\gamma$, and for both cytokines, the production was increased after supplementation (80 and 60\%) and after supplementation and exercise (85 and $88 \%$ ), respectively. These increases highlight the modulatory effects of FO and exercise in the elderly, which is helpful in restoring the immunity balance. In fact, one of the negative aspects of ageing is the reduction of the production of IL-2 and IFN- $\boldsymbol{\gamma}$, which play an important role in controlling diseases. These results corroborate the findings of Andrade et $a l^{(62)}$ where swimmers were supplemented for 6 weeks, which had a restoring effect on the TH1/TH2 balance that was mediated by increased production of IL- 2 and IFN- $\gamma$. This finding suggests that FO supplementation in the elderly during exercise has physiological regulatory action. Results must be viewed with caution, as it was not possible to use a large number of participants due to the longitudinal nature of the study. In addition, a rigid health status screening was not conducted and some of the participants may be suffering from early stages of diabetes or other diseases that may influence the results.

\section{Acknowledgements}

FO was kindly donated by Herbarium Foundation for Health and Research, Curitiba, Paraná, Brazil.

This research received no specific grant from any funding agency, commercial or not-for-profit sectors.

Contributions of authors are as follows: All authors have made substantial contribution to the manuscript, which involved an intervention (exercise training) programme, which required extensive laboratory analysis. This is an integrative research that involves different backgrounds and expertise. Dr A. L. F. R., L. C. F. and C. d. L. N. R. developed the study design, which was part of a PhD study. Authors contributed to data collection, conducting the training programme, data analysis and also to the final version of the manuscript. They all provided relevant intellectual contribution and were aware of the content of the manuscript.

There is no conflict of interest among the authors to publish the present study.

\section{References}

1. Gruver AL, Hudson LL \& Sempowski GD (2007) Immunosenescence of ageing. J Pathol 211, 144-156.

2. Simpson RJ \& Guy K (2010) Coupling aging immunity with a sedentary lifestyle: has the damage already been done? - a mini-review. Gerontology 56, 449-458.
3. Shaw AC, Joshi S, Greenwood H, et al. (2010) Aging of the innate immune system. Curr Opin Immunol 22, 507-513.

4. Wenisch C, Patruta S, Daxbock F, et al. (2000) Effect of age on human neutrophil function. J Leuk Biol 67, 40-45.

5. Derhovanessian E, Larbi A \& Pawelec G (2009) Biomarkers of human immunosenescence: impact of cytomegalovirus infection. Curr Opin Immunol 21, 440-445.

6. Simpson RJ, Lowder TW, Spielmann G, et al. (2012) Exercise and the aging immune system. Ageing Res Rev 11, 404-420.

7. Flynn MG, Fahlman M, Braun WA, et al. (1985) Effects of resistance training on selected indexes of immune function in elderly women. J Appl Physiol 86, 1905-1913.

8. Simopoulos AP (2002) The importance of the ratio of omega6/omega-3 essential fatty acids. Biomed Pharmacother 56, $365-379$

9. Simpson RJ, Cosgrove C, Ingram LA, et al. (2008) Senescent T-lymphocytes are mobilized into the peripheral blood compartment in young and older humans after exhaustive exercise. Brain Behav Immun 22, 544.

10. Keylock KT, Lowder T, Leifheit KA, et al. (2007) Higher antibody, but not cell-mediated, responses to vaccination in high physically fit elderly. J Appl Physiol 102, 1090-1098.

11. Shaikh SR \& Edidin M (2006) Polyunsaturated fatty acids, membrane organization, $\mathrm{T}$ cells, and antigen presentation. Am J Clin Nutr 84, 1277-1289.

12. Nieman DC (2003) Current perspective on exercise immunology. Curr Sports Med Rep 2, 239-242.

13. Rall LC, Roubenoff R, Cannon JG, et al. (1996) Effects of progressive resistance training on immune response in aging and chronic inflammation. Med Sci Sports Exerc 28, 1356-1365.

14. Fahlman M, Boardley D, Flynn MG, et al. (2000) Effects of endurance training on selected parameters of immune function in elderly women. Gerontology 46, 97-104.

15. Bermon S (2007) Airway inflammation and upper respiratory tract infection in athletes: is there a link? Exerc Immunol Rev 13, 6-14.

16. Woods JA, Ceddia MA, Wolters BW, et al. (1999) Effects of 6 months of moderate aerobic exercise training on immune function in the elderly. Mech Ageing Dev 109, 1-19.

17. Crist DM, Mackinnon LT, Thompson RF, et al. (1989) Physical exercise increases natural cellular-mediated tumor cytotoxicity in elderly women. Gerontology 35, 66-71.

18. Drella N, Kozdron E \& Szczypiorski P (2004) Moderate exercise may attenuate some aspects of immunosenescence. BMC Geriatrics $\mathbf{4}, 8$.

19. Kohut ML, Arntson BA, Lee W, et al. (2004) Moderate exercise improves antibody response to influenza immunization in older adults. Vaccine 22, 2298-2306.

20. Smith GI, Atherton P, Reeds DN, et al. (2011) Dietary omega3 fatty acid supplementation increases the rate of muscle protein synthesis in older adults: a randomized controlled trial. Am J Clin Nutr 93, 402-412.

21. Yehuda S, Rabinovitz S \& Mostofsky DI (2005) Essential fat acids on the brain: from infancy to aging. Neurobiol Aging 26, Suppl. 1, S98-S102.

22. Naliwaiko K, Araujo RLF, Fonseca RV, et al. (2004) Effects of fish oil on the central nervous system: a new potential antidepressant. Nutr Neurosci 7, 91-99.

23. Calder PC \& Kew S (2002) The immune system: a target for functional foods? Br J Nutr 88, S165-S177.

24. Farooqui AA (2009) Lipid mediators in the neural cell nucleus: their metabolism, signaling and association with neurological disorders. Neuroscientist 15, 392-407. 
25. Tur JA, Bibiloni MM, Sureda A, et al. (2012) Dietary sources of omega 3 fatty acids: public health risks and benefits. $\mathrm{Br} J$ Nutr 107, S23-S52.

26. Craig CL, Marshall AL, Sjostrom M, et al. (2003) International physical activity questionnaire: 12-country reliability and validity. Med Sci Sport Exerc 35, 1381-1395.

27. Rodacki CL, Rodacki AL, Pereira G, et al. (2012) Fish-oil supplementation enhances the effects of strength training in elderly women. Am J Clin Nutr 95, 428-436.

28. Simopoulos AP (2009) Evolutionary aspects of the diet omega-6: omega-3 fatty acid ratio: medical implications. World Rev Nutr Diet 100, 1-21.

29. Boyum A (1976) Isolation of lymphocytes, granulocytes and macrophages. Scand J Immunol 5, 9-15.

30. Bonatto SJR, Folador A, Aikawa J, et al. (2004) Lifelong exposure to dietary fish oil alters macrophage responses in Walker 256 tumor-bearing rats. Cell Immunol 231, 56-62.

31. Pick E \& Mizel M (1981) Rapid microassays for the measurement of superoxide and hydrogen peroxide production by macrophages in culture using an automatic enzyme immunoassay reader. J Immunol Meth 46, 211-226.

32. Pedersen BK \& Hoffman-Goetz L (2000) Exercise and the immune system: regulation, integration, and adaptation. Physiol Rev 80, 1055-1081.

33. Nieman DC, Henson DA, Gusewitch BJ, et al. (1993) Physical activity and immune function in elderly women. Med Sci Sports Exerc 25, 823-831.

34. Yan H, Kuroiwa A, Tanaka H, et al. (2001) Effect of moderate exercise on immune senescence in men. Eur J Appl Physiol 86, 105-111.

35. Ogawa K, Oka J, Yamakawa J, et al. (2003) Habitual exercise did not affect the balance of type 1 and type 2 cytokines in elderly people. Mech Ageing Dev 124, 951-956.

36. Beshgetoor D, Arrues S \& McGuire K (2004) Effect of competitive training on T-cell mediated immune function in Master's female athletes. Int J Sports Med 25, 553-558.

37. Nieman DC, Henson DA, Smith LL, et al. (2001) Cytokine changes after a marathon race. J Appl Physiol 91, 109-114.

38. Mazzeo RS, Cavanaugh P, Evans WJ, et al. (1998) American College of Sports Medicine position stand. Exercise and physical activity for older adults. Med Sci Sport Exerc 30, 992-1008.

39. Simpson RJ, McFarlin BK, McSporran C, et al. (2009) Toll-like receptor expression on classic and pro-inflammatory blood monocytes after acute exercise in humans. Brain Behav Immun 23, 232-239.

40. Haaland DA, Sabljic TF, Baribeau DA, et al. (2008) Is regular exercise a friend or foe of the aging immune system? a systematic review. Clin J Sport Med 18, 539-548.

41. Kapasi ZF, Ouslander JG, Schnelle JF, et al. (2003) Effects of an exercise intervention on immunologic parameters in frail elderly nursing home residents. J Gerontol A Biol Sci Med Sci 58, 636-643.

42. Raso V, Benard G, Silva Duarte DA, et al. (2007) Effect of resistance training on immunological parameters of healthy elderly women. Med Sci Sports Exerc 39, 2152-2159.

43. Tibana RA, Pereira GB, Souza JC, et al. (2013) Resistance training decreases 24-hour blood pressure in women with metabolic syndrome. Diabetol Metab Syndr 5, 27.
44. Bento PCB, Pereira G, Ugrinowitsch C, et al. (2010) Peak torque and rate of torque development in elderly with and without fall history. Clin Biomech 25, 450-454.

45. Calder PC (1998) n-3 Polyunsaturated fatty acids and mononuclear phagocyte function. In Medicinal Fatty Acids in Inflammation, pp. 1-28 [J Kremer, editor]. Basel: Springer Basel AG.

46. Kew T, Banerjee AM, Minihane YE, et al. (2003) Lack of effect of foods enriched with plant- or marine-derived $n-3$ fatty acids on human immune function. Am J Clin Nutr 77, 1287-1295.

47. Bonatto SJ, Oliveira HH, Nunes EA, et al. (2012) Fish oil supplementation improves neutrophil function during cancer chemotherapy. Lipids 47, 383-389.

48. Calder PC (2007) Immunomodulation by omega-3 fatty acids. Prostaglandins Leukot Essent Fatty Acids 77, 327-335.

49. Shaikh SR \& Edidin M (2008) Polyunsaturated fatty acids and membrane organization: elucidating mechanisms to balance immunotherapy and susceptibility to infection. Chem Phys Lipids 153, 24-33.

50. Schonfeld P \& Wojtczak L (2008) Fatty acids as modulators of the cellular production of reactive oxygen species. Free Radic Biol Med 45, 231-241.

51. Armah CK, Jackson KG, Doman I, et al. (2008) Fish oil fatty acids improve postprandial vascular reactivity in healthy men. Clin Sci (Lond) 114, 679-686.

52. Bedard K \& Krause KH (2007) The NOX family of ROS-generating NADPH oxidases: physiology and pathophysiology. Physiol Rev 87, 245-313.

53. Fulop T, Fouquet C, Allaire P, et al. (1997) Changes in apoptosis of human polymorphonuclear granulocytes with aging. Mech Ageing Dev 96, 15-31.

54. Fulop T (1994) Signal transduction changes in granulocytes and lymphocytes with ageing. Immunol Lett 40, 259-268.

55. Petkova DH, Momchilova AB \& Koumanov KS (1986) Age related changes in rat liver plasma membrane phospholipase A2 activity. Exp Gerontol 21, 187-193.

56. Nelson D \& Cox M (2000) Principles of Biochemistry, 3rd ed. New York: Worth Publishers pp. 28-39.

57. Bechoua S, Dubois M, Vericel E, et al. (2003) Influence of very low dietary intake of marine oil on some functional aspects of immune cells in healthy elderly people. BrJ Nutr 89, 523-531.

58. Grimble RF, Howell WM, O'Reilly G, et al. (2002) The ability of fish oil to suppress tumor necrosis factor- $\alpha$ production by peripheral blood mononuclear cells in healthy men is associated with polymorphisms in genes which influence TNF- $\alpha$ production. Am J Clin Nutr 76, 454-459.

59. Caruso C, Candore G, Colonna-Romano G, et al. (2005) Inflammation and life-span. Science 307, 208-209.

60. De Veale B, Brummel T \& Seroude L (2004) Immunity and aging: the enemy within? Aging Cell 3, 195-208.

61. Starkie R, Ostrowski SR, Jauffred S, et al. (2003) Exercise and IL-6 infusion inhibit endotoxin-induced TNF- $\alpha$ production in humans. FASEB J 17, 884-886.

62. Andrade PMM, Ribeiro BG, Bozza MT, et al. (2007) Effects of the fish-oil supplementation on the immune and inflammatory responses in elite swimmers. Prostaglandins Leukot Essent Fatty Acids 77, 139-145. 